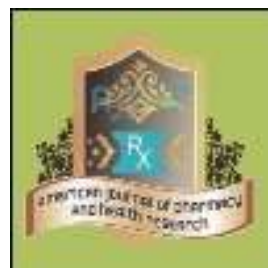

Research Article
AMERICAN JOURNAL OF PHARMACY AND HEALTH RESEARCH
www.ajphr.com

2018, Volume 6, Issue 02

ISSN: 2321-3647(online)

\title{
Development and Validation of High Performance Liquid Chromatography for the Determination of Domperidone and Esomeprazole in Their Pharmaceutical Formulation
}

\author{
Ahmed S. A. Ali ${ }^{1, *}$, Omnia I. M. Ali ${ }^{2}$, Abdel Fattah B. Farag', Maged F. Abdel Khalek \\ 1.Hefny Pharma Group, Cairo, Egypt \\ 2.Chemistry Department, Faculty of Science, Helwan University, Ain Helwan, Cairo, 11795, \\ Egypt \\ 3.Pharco Pharmaceutical Company, Alexandria, Egypt
}

\begin{abstract}
A new precise, accurate, robust and stability indicating high-performance liquid chromatographic method has been developed and validated for the simultaneous estimation of domperidone (DOM) and esomeprazole (ESO) in their pharmaceutical formulation. The proposed method carried out on Waters Symmetry C18 column ( $250 \mathrm{~mm}$ x $4.6 \mathrm{~mm}, 5.0 \mu \mathrm{m}$ particle size) using an isocratic elution technique at a column temperature of $30{ }^{\circ} \mathrm{C}$. The mobile phase was a mixture of $0.01 \mathrm{M}$ sodium acetate buffer: methanol $(45: 55 \mathrm{v} / \mathrm{v})$ and it was adjusted to $\mathrm{pH} 4.5$ using glacial acetic acid with a flow rate of $1 \mathrm{~mL} / \mathrm{min}$ and an injection volume of $20 \mu \mathrm{L}$. The retention times were 3.7 and $5.0 \mathrm{~min}$ with UV detection at $290 \mathrm{~nm}$ for DOM and ESO, respectively. The proposed method was linear over the concentration ranges of $0.04-60.0$ and $0.08-120.0 \mu \mathrm{g} / \mathrm{mL}$ for DOM and ESO, respectively. Limit of detection and limit of quantitation values were 0.48 and $1.44 \mu \mathrm{g} / \mathrm{mL}$ for DOM and 0.47 and $1.43 \mu \mathrm{g} / \mathrm{mL}$ for ESO, respectively. The method also exhibited good levels of recovery from $100.23 \%$ to $101.59 \%$ for DOM and from $99.74 \%$ to $101.57 \%$ for ESO. From the validation study, it was found that the method was specific, rapid, accurate and reproducible. The high percentage of recovery and low relative standard deviation confirm the suitability of the method for routine pharmaceutical analysis of both drugs separately or in their combined dosage form.
\end{abstract}

Keywords: HPLC; Esomeprazole; Domperidone; Validation; Formulation. 


\section{INTRODUCTION}

Domperidone (Scheme I), 5-chloro-1-[1-[3-(2,3-dihydro-2-oxo-1H-benz-imidazol-1-yl) propyl]4-piperidinyl]-1,3-dihydro-2H-benzimidazol-2-one, is a dopamine receptor antagonist, which is used as an antiemetic drug and is official in British Pharmacopoeia. Domperidone does not cross the blood-brain barrier, thus it has fewer adverse central nervous system effects than other dopamine antagonists ${ }^{[1,2]}$.

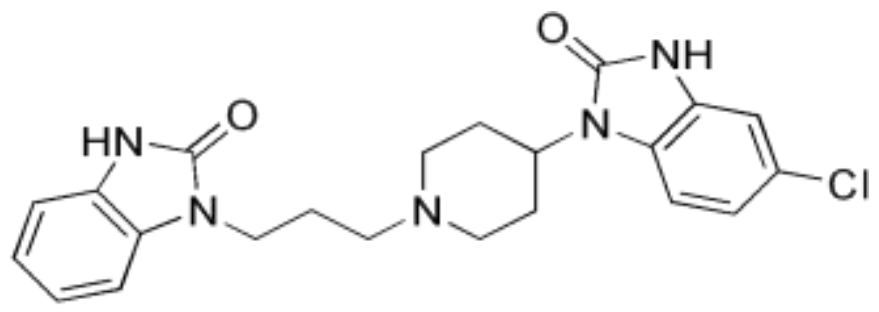

\section{Scheme I: Chemical structure of domperidone.}

Esomeprazole magnesium trihydrate (Scheme II), bis(5-me thoxy-2-[(S)-[(4-methoxy-3,5dimethyl-2-pyridinyl)methyl]sulfinyl-1H-benzimidazole-1-yl)magnesium Trihydrate, is an orally/intravenously administered proton pump inhibitor. Esomeprazole is a benzimidazole derivative and S-enantiomer of omeprazole ${ }^{[3,4]}$. Esomeprazole is used to treat gastro esophageal reflux disease (GERD), a condition in which backward flow of acid from the stomach causes heartburn and possible injury of the esophagus. Esomeprazole is also used to decrease the chance that people who are taking nonsteroidal anti-inflammatory drugs will develop ulcers. It is also used with other medications to treat and prevent the return of stomach ulcers caused by a certain type of bacteria (H. pylori).

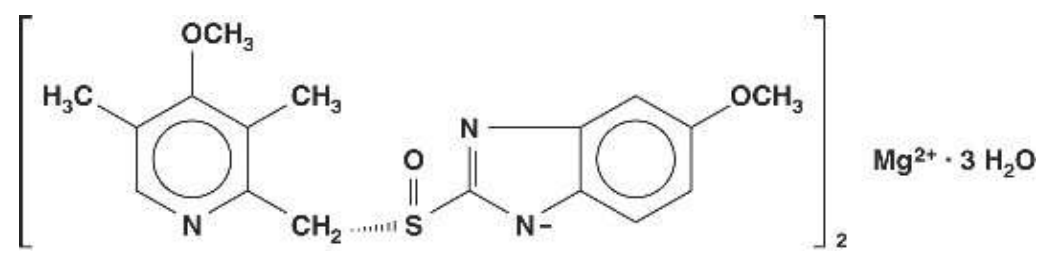

\section{Scheme II: Chemical structure of esomeprazole magnesium trihydrate}

Domperidone and esomeprazole combination is used for the treatment of gastro esophageal reflux disease. Literature survey reveals that few analytical methods were used for estimation of DOM and ESO combination in their dosage form ${ }^{[5-8]}$. Several techniques such as spectrophotometry, high performance liquid chromatography, Liquid chromatography-mass spectrometry, and high performance-thin layer chromatography have been reported in the literature for the individual determination of $\mathrm{DOM}^{[9,10]}$ and $\mathrm{ESO}^{[11-14]}$. Also, several techniques 
were reported for the determination of DOM in combinations with other drugs ${ }^{[15-20]}$, or for ESO in combinations with other drugs ${ }^{[21-22]}$.

The most of the currently published methods used mobile phases that contained high buffer concentration that would affect the columns life. In addition, no studies have been done on the method stability and specificity.

The objective of this work was to develop and validate an accurate, specific, precise and stability indicating HPLC method for the simultaneous determination of DOM and ESO in their dosage form.

\section{MATERIALS AND METHOD}

\section{Instrumentation and reagents}

Domperidone was gifted from EIPICO Pharmaceutical Company (Cairo, Egypt). Esomeprazole magnesium trihydrate was obtained from Precise Chemipharma PVT. LTD. (Mumbai, India). The used water was water for injection was purchased from Otsuka pharmaceutical industry (Cairo, Egypt). Methanol HPLC grade was purchased from J.T. Baker (Phillipsburg, USA). Glacial acetic acid was purchased from Duksan Pure Chemicals Co., Ltd. (South Korea) and sodium acetate was supplied from El- Nasr pharmaceutical Co. (Cairo, Egypt). Ranidom-O tablets were labeled to contain $10.0 \mathrm{mg}$ domperidone and esomeprazole magnesium trihydrate equivalent to $20.0 \mathrm{mg}$ esomeprazole per tablet (Mankind pharma Ltd., India). All experiments were performed on Waters alliance e2695 HPLC with 2489-UV/Vis detector (WATERS, USA). Symmetry C18 column ( $250 \mathrm{~mm}$ x $4.6 \mathrm{~mm}, 5.0 \mu \mathrm{m}$ particle size) (WATERS, USA), the mobile phase consisted of $0.01 \mathrm{M}$ sodium acetate ( $\mathrm{pH} 4.5$ using glacial acetic acid) and methanol in a ratio of $(45: 55, \mathrm{v} / \mathrm{v})$. Power sonic 410 sonication (HWASHIN technology, Korea) was used to degas the mobile phase and it was filtered using $0.45 \mu \mathrm{m}$ cellulose nitrate filter prior to use.

\section{Preparation of standard stock solutions, sample solution and mobile phase}

\section{Standard stock solutions}

Standard DOM powder $(20.0 \mathrm{mg})$ was accurately weighed and transferred into $50 \mathrm{~mL}$ volumetric flask and dissolved in methanol. It was further diluted to $50 \mathrm{~mL}$ with methanol to prepare a stock standard solution of $400 \mu \mathrm{g} / \mathrm{mL}$. Standard esomeprazole magnesium trihydrate powder that equivalent to $40 \mathrm{mg}$ esomeprazole was accurately weighed and transferred into $50 \mathrm{~mL}$ volumetric flask and dissolved in methanol. It was further diluted to $50 \mathrm{~mL}$ with methanol to prepare a stock standard solution of $800 \mu \mathrm{g} / \mathrm{mL}$.

\section{Standard mixture solution}


$5 \mathrm{~mL}$ of both DOM stock solution and ESO stock solution was transferred into $50 \mathrm{~mL}$ volumetric flask and diluted to the mark with methanol to obtain a final concentration of $40 \mu \mathrm{g} / \mathrm{mL}$ of DOM and $80 \mu \mathrm{g} / \mathrm{mL}$ of ESO.

\section{Sample solution}

Contents of twenty tablets were crushed, weighed, mixed and a quantity of the powder equivalent to $10 \mathrm{mg}$ of DOM and $20 \mathrm{mg}$ of ESO was transferred into $50 \mathrm{~mL}$ measuring flask and dissolved in methanol. The solution was filtered through $0.45 \mu \mathrm{m}$ cellulose nitrate filter. $5 \mathrm{ml}$ of the filtrate was transferred to $25 \mathrm{~mL}$ volumetric flask and diluted to the mark with methanol to get a final concentration of $40 \mu \mathrm{g} / \mathrm{mL}$ of DOM and $80 \mu \mathrm{g} / \mathrm{mL}$ of ESO.

\section{Preparation of mobile phase}

The mobile phase was prepared by mixing buffer and methanol in 45:55 (v/v) ratio. The buffer was prepared by dissolving $0.82 \mathrm{~g}$ of sodium acetate in water for injection and the final volume was made up to $1000 \mathrm{~mL}$ with the same solvent. Then the $\mathrm{pH}$ of the buffer was adjusted to 4.5 with glacial acetic acid, then filtered by passing through $0.45 \mu \mathrm{m}$ membrane filter and degassed before use.

\section{Method validation}

The developed chromatographic method was validated following ICH guidance for specificity, linearity, limit of detection, limit of quantification, accuracy, precision and robustness ${ }^{[23]}$.

\section{RESULTS AND DISCUSSION}

\section{System suitability}

A system suitability test was carried out through the evaluation of the peaks performance to verify that the equipment and the proposed method were reliable for the analysis to be performed. Table 1 shows the results for the studied parameters. Theoretical plates number of the column was much better for analysis i.e. $\geq 5000$. The tailing factor was also within range (1.01.1). Moreover, the USP resolution of ESO peak $\geq 4.0$ and the calculated values of relative standard deviation (RSD) for the peak areas (mean of 6 replicates) also within acceptance criteria. Depending on these data, it can be concluded that the proposed method will be suitable for routine analysis.

Table 1: System suitability parameters for DOM and ESO using the proposed method.

\begin{tabular}{lll}
\hline Parameter & DOM & ESO \\
\hline Theoretical Plates & 6009 & 7521 \\
Symmetry Factor & 1.09 & 0.96 \\
\%RSD (Peak area) & 1.06 & 1.1
\end{tabular}




\begin{tabular}{lll} 
Resolution & - & 4.27 \\
Tailing factor & 1.1 & 1.0 \\
\hline
\end{tabular}

The chromatograms of DOM and ESO in their combination using the proposed method are shown in Figure 1.
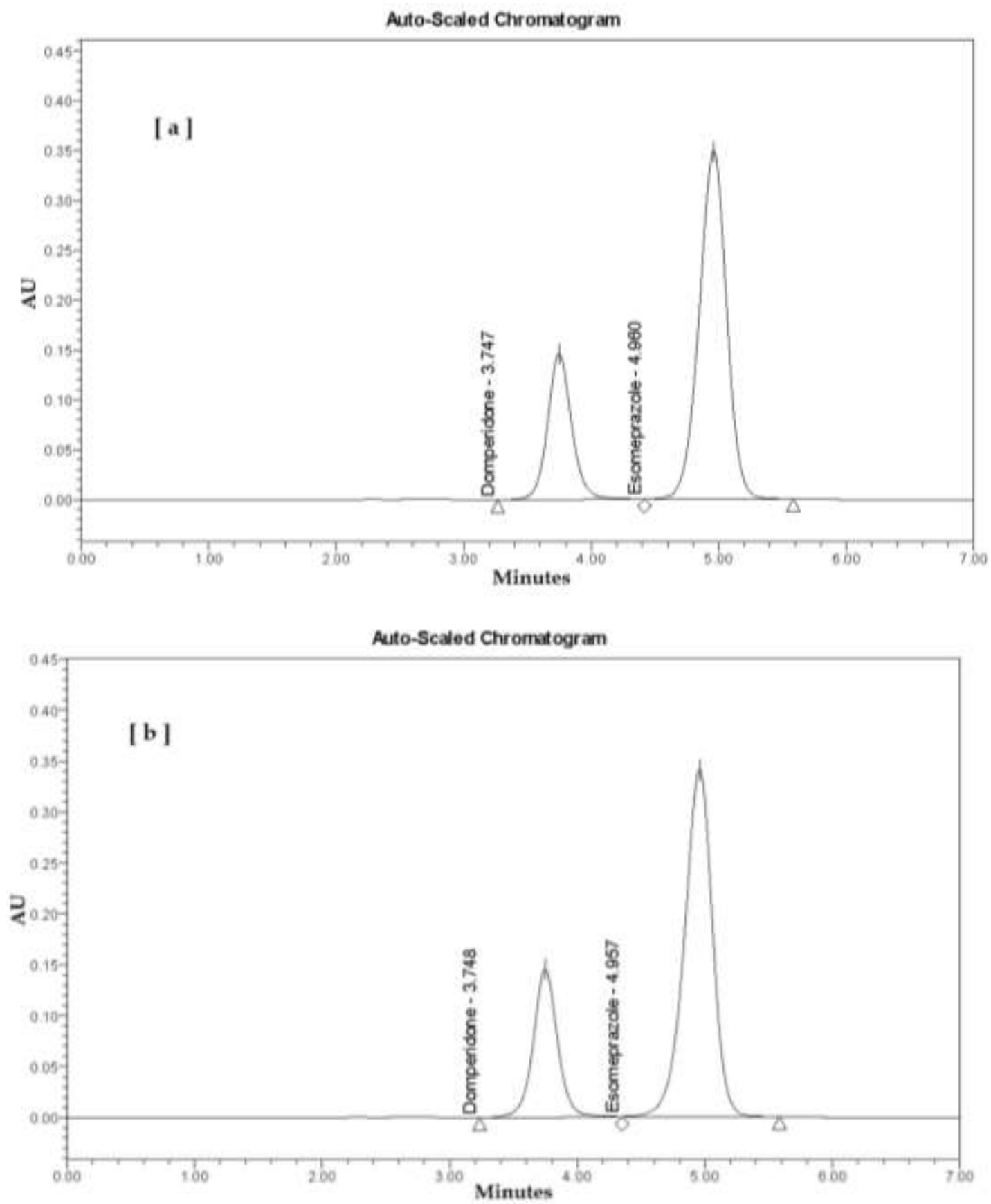

Figure 1: Chromatograms of $40 \mu \mathrm{g} / \mathrm{mL}$ of DOM and $80 \mu \mathrm{g} / \mathrm{mL}$ of ESO in [a] standard mixture solution and in [b] tablet dosage form. Linearity 
The linearity of the method was checked by preparing different concentrations of DOM ranging from 0.04 to $60.0 \mu \mathrm{g} / \mathrm{mL}$ and for ESO from 0.08 to $120.0 \mu \mathrm{g} / \mathrm{mL}$. The linearity of the calibration graphs and adherence of the system to Beer's law were validated by the high values of the correlation coefficient of 0.9999 for both DOM and ESO. The results obtained for these calibration graphs are provided in Table 2 and depicted in Figure 2.

Table 2:Linearity parameters for DOM and ESO using the proposed method.

\begin{tabular}{lll}
\hline Parameter & DOM & ESO \\
\hline Range $(\mu \mathrm{g} / \mathrm{mL})$ & $0.04-60$ & $0.08-120$ \\
Slope & 47498 & 64993 \\
Intercept & 2120 & 9063 \\
Correlation coefficient $\left(\mathrm{R}^{2}\right)$ & 0.9999 & 0.9999 \\
LOD $(\mu \mathrm{g} / \mathrm{mL})$ & 0.48 & 0.47 \\
LOQ $(\mu \mathrm{g} / \mathrm{mL})$ & 1.44 & 1.43 \\
\hline
\end{tabular}
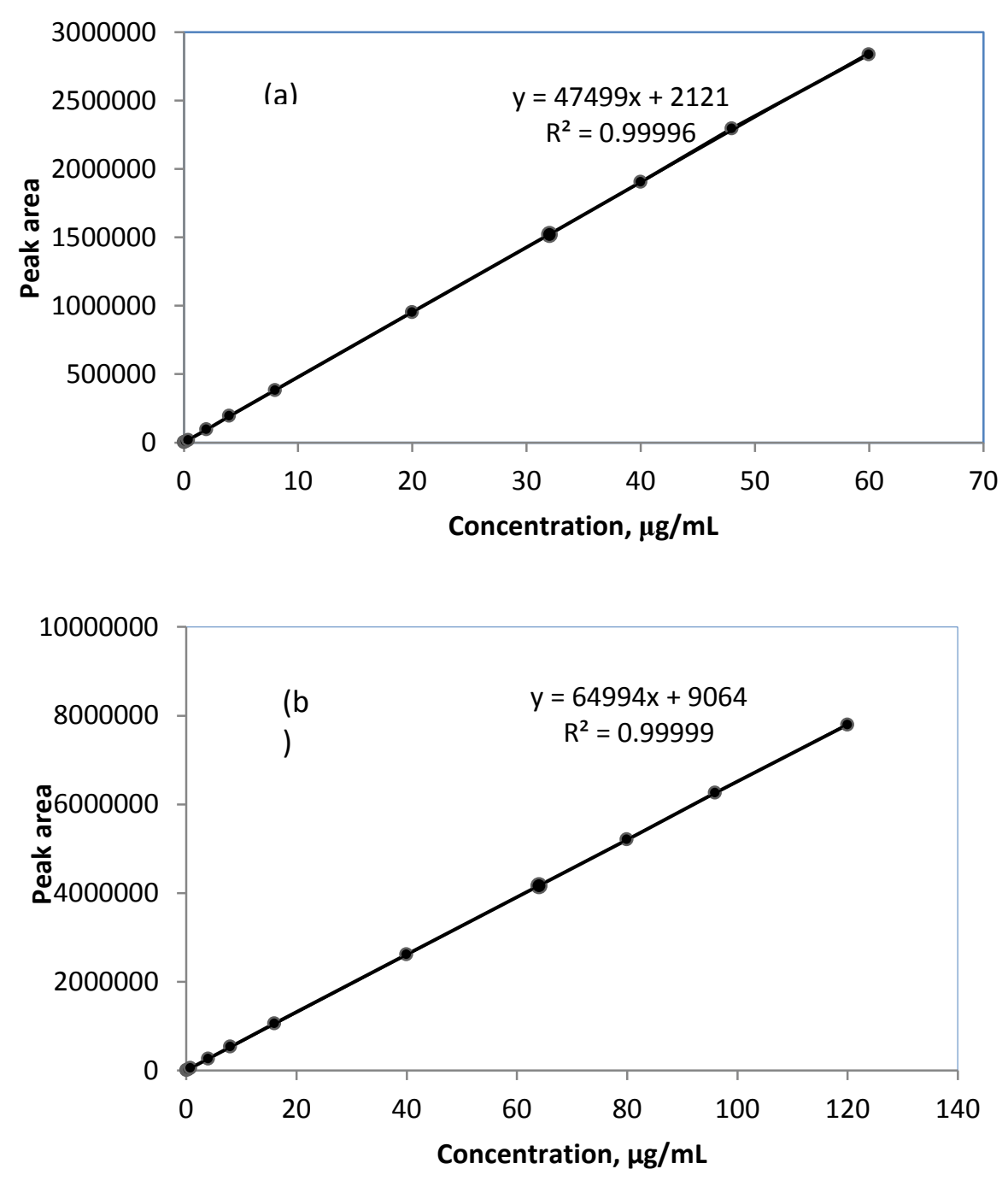

Figure 2: Calibration curves for [a] DOM and [b] ESO. 


\section{Accuracy}

The accuracy of the method was determined by calculating the \% recovery of DOM and ESO by analyzing DOM and ESO in their dosage forms at five concentration levels each in three times Table 3.

Table 3: Accuracy data for DOM and ESO using the proposed method.

\begin{tabular}{|c|c|c|c|c|c|}
\hline \multirow[t]{2}{*}{ Drug } & \multirow{2}{*}{$\begin{array}{l}\text { Concentration } \\
(\mu \mathrm{g} / \mathrm{mL})\end{array}$} & \multicolumn{2}{|c|}{ Accuracy } & \multirow{2}{*}{$\begin{array}{l}\% \text { Mean } \\
\text { recovery } \\
\pm \mathrm{SD}\end{array}$} & \multirow[b]{2}{*}{$\%$ RSD } \\
\hline & & $\begin{array}{l}\text { Amount } \\
\text { found }{ }^{\mathrm{a}}\end{array}$ & $\begin{array}{l}\% \\
\text { Recovery }\end{array}$ & & \\
\hline \multirow[t]{5}{*}{$\mathrm{DOM}$} & 20.0 & 20.31 & 101.59 & & \\
\hline & 32.0 & 32.07 & 100.23 & & \\
\hline & 40.0 & 40.40 & 101.01 & 100.78 & 0.55 \\
\hline & 48.0 & 48.34 & 100.72 & \pm 0.55 & \\
\hline & 60.0 & 60.36 & 100.36 & & \\
\hline \multirow{5}{*}{ ESO } & 40.0 & 40.11 & 100.29 & & \\
\hline & 64.0 & 64.48 & 100.76 & & \\
\hline & 80.0 & 81.25 & 101.57 & 100.70 & 0.71 \\
\hline & 96.0 & 97.09 & 101.14 & \pm 0.71 & \\
\hline & 120.0 & 119.61 & 99.74 & & \\
\hline
\end{tabular}

a mean of three different samples for each concentration

\section{Precision}

The repeatability of the analytical method was evaluated by assaying three sample solutions of DOM and ESO within the same day and under the same experimental conditions (Intra-Day). Intermediate precision was evaluated by assaying similar solutions on three consecutive days. The peak areas were determined and compared and the precision was expressed as $\%$ relative standard deviation (RSD\% <2). From the data obtained in Table 4, the developed RP-HPLC method was found to be precise.

Table 4: Precision data for DOM and ESO using the proposed method.

\begin{tabular}{|c|c|c|c|c|c|}
\hline \multirow[t]{2}{*}{ Drug } & \multirow{2}{*}{$\begin{array}{l}\text { Concentration } \\
(\mu \mathrm{g} / \mathrm{mL})\end{array}$} & \multicolumn{2}{|c|}{ Intra-day precision } & \multirow{2}{*}{$\begin{array}{l}\text { \% Mean } \\
\text { recovery } \\
\pm \mathrm{SD}\end{array}$} & \multirow[t]{2}{*}{$\%$ RSD } \\
\hline & & $\begin{array}{l}\text { Amount } \\
\text { found }^{\mathrm{a}}\end{array}$ & $\begin{array}{l}\% \\
\text { Recovery }\end{array}$ & & \\
\hline \multirow{3}{*}{ DOM } & 32.0 & 32.07 & 100.23 & 100.65 & \multirow[t]{3}{*}{0.40} \\
\hline & 40.0 & 40.40 & 101.01 & \multirow[t]{2}{*}{ \pm 0.40} & \\
\hline & 48.0 & 48.34 & 100.72 & & \\
\hline \multirow{3}{*}{ ESO } & 64.0 & 64.48 & 100.76 & 101.16 & \multirow[t]{3}{*}{0.41} \\
\hline & 80.0 & 81.25 & 101.57 & \multirow[t]{2}{*}{ \pm 0.41} & \\
\hline & 96.0 & 97.09 & 101.14 & & \\
\hline \multirow[t]{2}{*}{ Drug } & \multirow{2}{*}{$\begin{array}{l}\text { Concentration } \\
(\mu \mathrm{g} / \mathrm{mL})\end{array}$} & \multicolumn{2}{|c|}{ Inter-day precision } & \multirow{2}{*}{$\begin{array}{l}\text { \% Mean } \\
\text { recovery } \\
\pm \mathrm{SD}\end{array}$} & \multirow[t]{2}{*}{$\%$ RSD } \\
\hline & & $\begin{array}{l}\text { Amount } \\
\text { found }^{\mathrm{a}}\end{array}$ & $\begin{array}{l}\% \\
\text { Recovery }\end{array}$ & & \\
\hline & 32.0 & 31.78 & 99.32 & 100.08 & 0.67 \\
\hline DOM & 40.0 & 40.12 & 100.31 & \pm 0.67 & \\
\hline
\end{tabular}




\begin{tabular}{llllll} 
& 48.0 & 48.29 & 100.61 & & \\
& 64.0 & 63.62 & 99.41 & 100.11 & 0.61 \\
ESO & 80.0 & 80.30 & 100.37 & \pm 0.61 & \\
& 96.0 & 96.51 & 100.54 & & \\
\hline
\end{tabular}

${ }^{a}$ mean of three different samples for each concentration

\section{Robustness}

Robustness is the measure of method capacity to retain unaffected by deliberate small changes in the chromatographic conditions. The impact of flow rate $( \pm 0.03)$ and effect of temperature $\left( \pm 2^{\circ} \mathrm{C}\right)$ were evaluated on the important system suitability factors such as retention time; theoretical plates and tailing factor. The results are shown in Table 5.

Table 5: Robustness studies of DOM and ESO.

\begin{tabular}{llllll}
\hline Drug & Parameters & Variation & RT (min) & Tailing factor & Plate count \\
\hline DOM & Flow rate & 1.27 & 3.89 & 1.19 & 6407 \\
& $(\mathrm{~mL} / \mathrm{min})$ & 1.3 & 3.76 & 1.09 & 6001 \\
& & 1.33 & 3.73 & 1.20 & 6371 \\
\cline { 2 - 6 } & Temperature, ${ }^{\circ} \mathrm{C}$ & 28 & 3.82 & 1.19 & 6342 \\
& & 30 & 3.77 & 1.09 & 6009 \\
& & 32 & 3.82 & 1.17 & 6386 \\
\hline ESO & Flow rate & 1.27 & 5.07 & 1.04 & 8058 \\
& (mL/min) & 1.3 & 4.98 & 0.95 & 7510 \\
& & 1.33 & 4.89 & 1.05 & 8049 \\
\cline { 3 - 6 } & Temperature, ${ }^{\circ} \mathrm{C}$ & 28 & 4.99 & 1.04 & 7984 \\
& & 30 & 4.98 & 0.96 & 7534 \\
& & 32 & 5.00 & 1.03 & 8012 \\
\hline
\end{tabular}

\section{Stability of standard solutions}

$\%$ RSD of the standard solutions peaks' areas within 7 days was calculated. The standard solutions were stored in the refrigerator and analyzed on the first day, the third day and the $7^{\text {th }}$ day and injected three times. The low values of the percentage relative standard deviation of $1.95 \%$ and $1.27 \%$ for DOM and ESO, respectively, indicate that the standard solutions were stable for more than 7 days if they were stored in the refrigerator.

\section{Stress testing}

Specificity is the ability of the method to measure the analyte response in the presence of its degradation products. The specificity of the developed RP-HPLC method for DOM and ESO was carried out in the presence of their degradation products. Stress studies were performed for DOM and ESO in their bulk drugs to provide an indication of the stability indicating property and specificity of the proposed method. Aliquots of DOM and ESO standard solutions were treated as follows: (a) oxidation study with $3.0 \% \mathrm{H}_{2} \mathrm{O}_{2}$; (b) acidic stress with $1.0 \mathrm{~N} \mathrm{HCl}$; (c) 
alkaline treatment with $1.0 \mathrm{~N} \mathrm{NaOH}$. In all these cases, treatment was carried out at $60^{\circ} \mathrm{C}$ for 2 hours and they neutralized before injection in the chromatograph. For temperature stress studies, the standard solutions were kept at $80^{\circ} \mathrm{C}$ for 2 hours. This was done to evaluate the ability of the proposed method to separate DOM and ESO from their degradation product products. Results are shown in Table 6.

Table 6: Results of stress testing.

\begin{tabular}{llcccc}
\hline Drug & Parameters & Acid & Base & Oxidation & Heat 80 ${ }^{\mathbf{C}}$ \\
\hline DOM & Recovery \% & 66.2 & 95.9 & 80.1 & 99.4 \\
& Resolution & 2.4 & 4.1 & 3.9 & 4.7 \\
& Plate Count & 3800 & 4014 & 3451 & 2359 \\
\hline \multirow{2}{*}{ ESO } & Recovery \% & 3.3 & 92.4 & 0.2 & 81.8 \\
& Resolution & 4.5 & 6.1 & 4.1 & 2.4 \\
& Plate Count & 2361 & 5808 & 4024 & 3046 \\
\hline
\end{tabular}

\section{Application of the proposed method to dosage form}

The developed method was used for the quantitative estimation of DOM and ESO in a commercial dosage form (Ranidom-O tablets). The sample was analyzed six times. Results of recovery are shown in Table 7. As indicated from the Table, none of the tablet ingredients interfered with the DOM and ESO peaks.

Table 7: Results of the marketed product.

\begin{tabular}{lllll}
\hline Marketed formulation & Drug & Assay \% & SD & \% RSD \\
\hline Ranidom-O & DOM: $10 \mathrm{mg}$ & 99.2 & 0.71 & 0.72 \\
& ESO: $20 \mathrm{mg}$ & 99.3 & 0.85 & 0.86 \\
\hline
\end{tabular}

${ }^{\mathrm{a}}$ Mean of six different samples

\section{CONCLUSION}

A simple, precise, accurate and stability indicating method was developed for the quantitative estimation of domperidone and esomeprazole in bulk drug and marketed pharmaceutical formulation without any interference from the excipients. The method was very simple and specific since both the drugs' peaks were well separated. The developed method offered several advantages such as rapid, cost-effective, simple mobile phase and sample preparation steps, improved sensitivity and comparative short run time. As the method able to separate the parent drug from degradation products, it can be employed as a stability indicating method for determination of DOM and ESO in the combined dosage form or separately. The lack of extraction procedures makes the method especially suitable for routine quality control analysis work particularly when large numbers of samples are encountered. 


\section{REFERENCES}

1. Akkamma HG, Sai Kumar S, Chandanam S, Sreenivasa Rao T, Sukanya K, Manogna K. Development and validation of new analytical method for simultaneous estimation of domperidone and rabeprazole in pharmaceutical dosage forms. Res. J. Pharm. Biol. Chem. Sci. 2012; 3: 705-712.

2. Sivakumar T, Manavalan R, Valliappan K. Development and validation of a reversedphase HPLC method for simultaneous determination of domperidone and pantoprazole in pharmaceutical dosage forms. Acta J. Chromatogr. 2007; 18: 130-142.

3. Sojitra C, Rajput S. Development and validation of RP-HPLC method for simultaneous estimation of naproxen and esomeprazole magnesium trihydrate in combined pharmaceutical formulation. Int. J. Pharm. Sci. 2012; 4: 533-537.

4. Poornima AN, Satishkumar SA, Manzoor A, Vijaya K C, Ravi MC, Anil Kumar SM. RPHPLC method development and validation for simultaneous estimation of esomeprazole and ondansetron in combined tablet dosage form. World J. Pharm. Sci. 2015; 4: 10411051.

5. Sharma S. and Sharma MC. Densitometric method for the quantitative determination of esomeprazole and domperidone in dosage forms. American-Eurasian J. Toxicol. Sci. 2011; 3: 143-148.

6. Maheshwari DG, Trivedi PD. Simultaneous estimation of esomeprazole and domperidone in combined dosage form by HPLC. Int. J. Appl. Sci. Eng. 2011; 9: 187194.

7. Maheshwari DG, Trivedi PD. Estimation of esomeprazole and domperidone by absorption ratio method in pharmaceutical dosage forms. Int. J. Chem. Res. 2010; 2: 1598-1605.

8. Dudhe PB, Shinde AP, Salgar K. Development and validation of analytical methods for simultaneous estimation of domperidone and esomeprazole magnesium in bulk and in pharmaceutical formulations using UV-visible spectroscopy. Int. J. Chem. Res. 2014; 6: 1501-1508.

9. Suparna1 S, Kumar SA, Ompal S, Kumar CA, Vikrant V, Kumar AR, Kumar SU. RPHPLC method development and validation of domperidone in solid dosage form. Pharm. J. Innovation 2012; 1: 16-20. 
10. Alarfaj NA, Mostafa AA, Al-Ghamdi ZA. Spectrophotometric determination of domperidone in its pharmaceutical formulation through charge transfer complexation reactions. Asian J. Chem. 2012; 25: 7377-7380.

11. Parthiban C, Divya SM, Pallavi V, Sowmya B, Prathyusha V. Method Development and validation for determination of esomeprazole in tablet dosage form by RP-HPLC method. Int. Res. J. Pharm. 2012; 3: 274-276.

12. Khalil MT, Usman M, Khan GM, Awan SB, Bibi H, Siddiqua A. HPLC method development and validation for the estimation of esomeprazole in bulk and pharmaceutical dosage form. Int. J. Drug Dev. Res. 2012; 4: 252-256.

13. Gawande V, puranik M. Development and validation of RP-HPLC method for estimation of esomeprazole magnesium in solid dosage form. J. Pharm. Res. 2012; 5: 5074-5075.

14. Mogili R, Kanala K, Kottapalli C, Rao.Chandu B, Reddy B. Quantification of esomeprazole in human plasma by liquid chromatography tandem mass spectrometry and its application to bioequivalence study. Sch. Res. Library 2011; 3: 138-145.

15. Kumar PR, Prakash PB, Krishna MM, Yadav MS, Deepthi CA. Simultaneous estimation of domperidone and pantoprazole in solid dosage form by UV spectrophotometry. E- J. Chem. 2016; 3: 142-145.

16. Aanandhi MV, Thiyagarajan N, Koilraj M, Shanmugasundaram P, Sujatha R. Simultaneous estimation of domperidone and lansoprazole in capsule formulation by HPTLC method. Rasayan J. Chem. 2009; 2: 15-17.

17. Vanka AK, Voodikala A, Simhari SV, Atla SR, Tata S. Development and validation of RP-HPLC method for simultaneous estimation of famotidine and domperidone in pharmaceutical dosage form. Int. J. Pharm. Sci. 2013; 5: 223-227.

18. Chitlange SS, Mulla AI, Pawbake GR, Wankhede SB. A validated RP-HPLC method for simultaneous estimation of dexrabeprazole and domperidone in pharmaceutical dosage form. Pelagia Res. Library 2010; 1: 42-47.

19. Rao GS, Rao AB, Reddy GR, Abdul-Shoeb M, Olabamiwo1 OM, Rao JV. RP-HPLC method for simultaneous estimation of domperidone and pantoprazole in capsule dosage form. Sch. Res. Library 2012; 4: 1712-1720.

20. Appasaheb HS, Shankar DP, Atharam DV, Subhash KP. Simultaneous estimation and validation of paracetamol and domperidone in bulk and tablet dosage form by using different spectrophotometric method. Int. Res. J. Pharm. 2013; 4: 180-183. 
21. Patel D, Patel N, Vaishy R, Patel V, Solanki C, Patel M. Development and validation of RP-HPLC method for simultaneous estimation of aspirin and esomeprazole magnesium in tablet dosage form. J. Chem. 2013; 1: 1-5.

22. Patel R, Kakadiya J, Patel P, Shah N. Development and validation of second order derivative spectrophotometric method for simultaneous estimation of levosulpiride and esomeprazole in combined pharmaceutical formulation. Int. Res. J. Pharm. Res. Biol. 2014; 3: 785-798.

23. ICH harmonized tripartite guideline (validation of analytical procedures). 2005; 3: 1-13.

AJPHR is

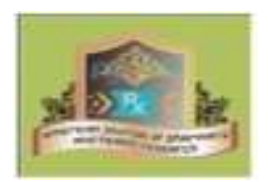

Peer-reviewed

monthly

Rapid publication

Submit your next manuscript at

editor@ajphr.com / editor.ajphr@gmail.com 